\title{
Financial and Environmental Cost-Benefit Analyses Support the Continuation of Government Incentives for Solar Power
}

\section{Ryan Himes, London Withers, Alyssa Black}

Olivet Nazarene University, Department of Biological Sciences, Bourbonnais, IL

http://doi.org/10.38126/JSPG170109

Corresponding author: rdhimes@olivet.edu

Keywords: solar energy; renewable energy; investment tax credit; government incentive; climate change; solar renewable energy credit; solar renewable energy certificate

Executive Summary: Solar power is a source of clean, renewable energy that can help consumers reduce their carbon footprints and curb climate change. In recent years, government incentives, along with improvements in efficiency and reduced costs, have made solar power financially beneficial for consumers as well. In order to accurately analyze the costs and benefits of a potential solar project, many factors must be considered. These include the size of the solar array, the amount of sun exposure, the lifespan of the panels and inverters, the lifespan of the roof or other foundation, the current and future price of utility-provided electricity, and the amount of government incentives offered. These factors are described in detail throughout this article, and the analysis reveals that government incentives for solar power projects make a substantial positive impact on the financial feasibility. We find that the US federal and state governments should continue their incentive programs in order to prompt more organizations to transition to solar power and thereby reduce greenhouse gas emissions.

\section{Introduction}

Americans consume over 90 exajoules $\left(2.5 \times 10^{13}\right.$ kilowatt-hours) of energy annually for transportation, electricity production, manufacturing, and other activities (British Petroleum 2019). The vast majority (83\%) of this energy comes from the combustion of fossil fuels (British Petroleum 2019), which are estimated to run out around the year 2110 at our current rate of use (Perez and Perez 2009). Furthermore, burning fossil fuels for energy increases the levels of greenhouse gases and pollutants in the atmosphere and directly contributes to climate change (IPCC 2014). In order to reach the main goal of the Paris Climate Agreement, which is to limit the increase in average global temperature to two degrees Celsius above pre-industrial levels (United Nations 2015), the global economy urgently needs to transition away from fossil fuels and deploy renewable sources of energy. Yet, instead of embracing this goal, the United States has recently withdrawn from the Paris Agreement. This is despite the fact that $67 \%$ of adults in the US say that the federal government is not doing enough to curb climate change and $64 \%$ say that it should make protecting the environment a top priority (Funk and Kennedy 2019).

\section{i. Sustainability of solar photovoltaic panels}

One way to accomplish the goal of the Paris Agreement would be to increase the quantity of energy supplied by renewable sources through the deployment of solar photovoltaic panels. Solar panels produce energy from freely available radiation from the sun, with no emissions. Solar energy is a sustainable and abundant resource that has the potential to greatly exceed the energy needs of global residences and commercial businesses (Perez and Perez 2009). In fact, if all the energy delivered to the earth by the sun in one hour could be captured and converted to usable power, it would be about equal to the amount of energy consumed by the global economy in one year (Crabtree and Lewis 2007). Although sunlight is intermittent, when paired with energy storage technologies such as batteries, solar 
arrays can provide uninterrupted power to users. The components of solar panels are also completely recyclable (mostly glass, plastic, aluminum, and silicon; see Figure 1), opening the possibility of achieving closed-loop recycling of materials after they are harvested (Weckend, Wade, and Heath 2016). Therefore, solar power has the potential to be a completely sustainable energy source.

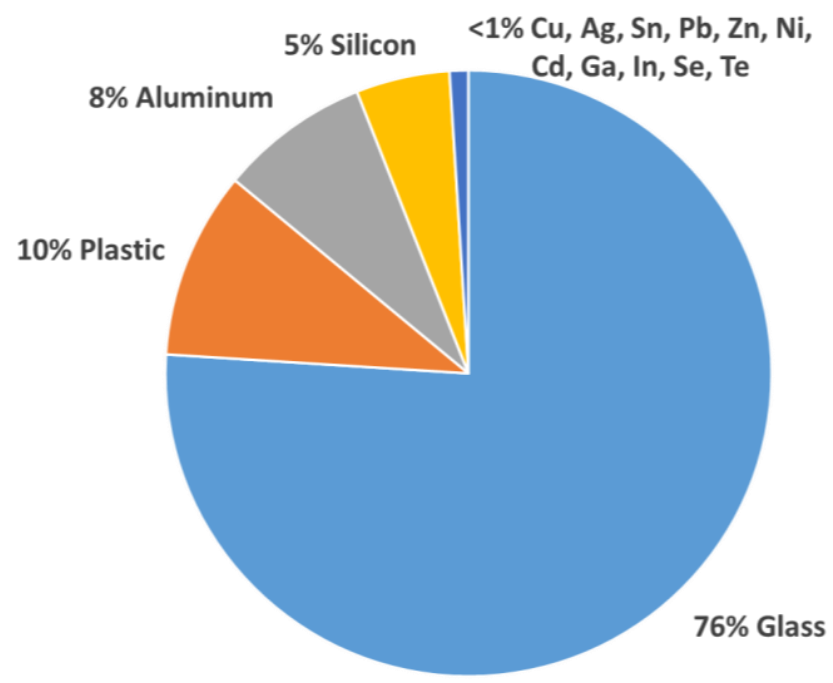

Figure 1: Composition by weight of crystalline silicon solar photovoltaic panels, the oldest and most prevalent type of solar panel (adapted from Weckend, Wade, and Heath 2016).

\section{ii. Cost of solar energy}

The cost of solar energy is now typically lower than traditional fossil fuel sources. While the sunlight itself is completely free and abundant, the price of the panels has dropped significantly over the last few decades, and is likely to continue to drop further (Warburg 2019; Goodstein and Lovins 2019). Taking into consideration the upfront purchase and installation costs, a levelized cost of energy (LCOE) can be calculated. A typical LCOE for utility-scale solar energy is currently around 4.1 cents per kilowatt-hour (kWh; Lazard 2018). In contrast, the average cost of electricity from traditional sources of energy in the US is currently 10.3 cents per $\mathrm{kWh}$, and typically increases by $3.6 \%$ annually (based on the last 60 years of price data; U.S. Energy Information Administration 2019).

\section{Analysis of government incentive programs}

Despite the potential cost savings over the long-term, the initial investment required to develop a solar array may be prohibitively expensive for many would-be users. Governmental incentivization has been used in the past and is currently used at multiple levels to help defray the initial costs of solar development and encourage investors. A federal investment tax credit (ITC) of 30\% was inaugurated in 2006. This rate decreased to $26 \%$ in 2020 , is scheduled to decrease to $22 \%$ in 2021 , and then to $10 \%$ for 2022 and beyond for the commercial sector, while dropping to zero for residences (Figure 2; Stokes and Breetz 2018).

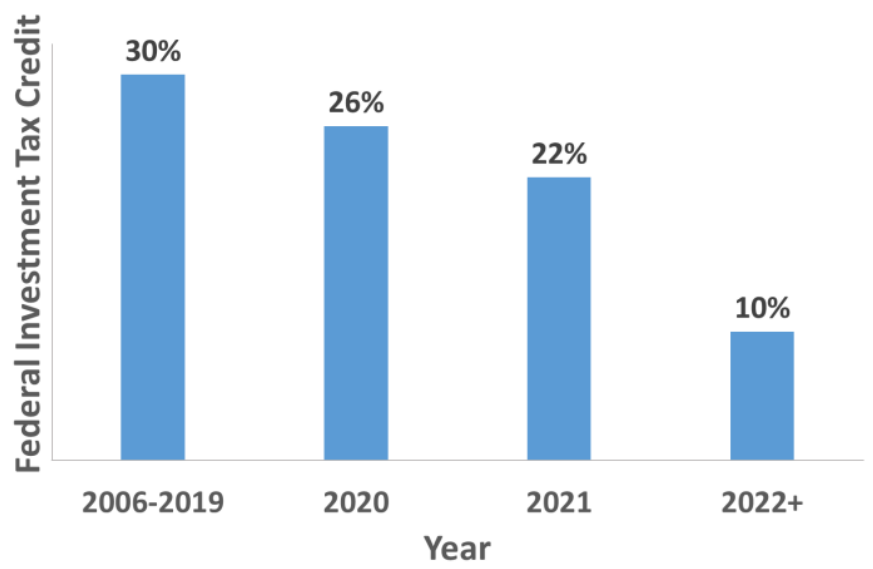

Figure 2: The value of the federal investment tax credit for solar and other renewable energy installations over time (adapted from Stokes and Breetz 2018). After 2021, the credit will be set permanently to $10 \%$ for commercial installations ( $0 \%$ for residential).

\section{i. State-level incentive programs}

Many states additionally have their own incentive programs. Through its Future Energy and Jobs Act, Illinois set a goal of sourcing $25 \%$ of its electricity from renewables by 2025 (Myers 2019). One of the primary means by which the state is accomplishing this goal is through the creation of a market for Solar Renewable Energy Credits (SRECs). The Illinois Power Agency purchases these SRECs from the owners of solar arrays to help offset the cost of their installations (Myers 2019). When combined with federal tax credits, the funds gained from the sale of these SRECs can substantially decrease the amount of time required for a solar array to become financially profitable (Figure 3). The funding for the purchase of these credits comes from all end-users of electricity in the state, in the form of small fees on users' electric bills. Therefore, the SRECs can be viewed as state- 
mandated cost-sharing among consumers in order to fund solar developments. Illinois's SREC program helped make the state the second largest creator of solar jobs in the country in 2018 (Ruppenthal 2019). However, like the federal ITC, Illinois's SREC benefits are now rapidly decreasing (Lydersen 2020).

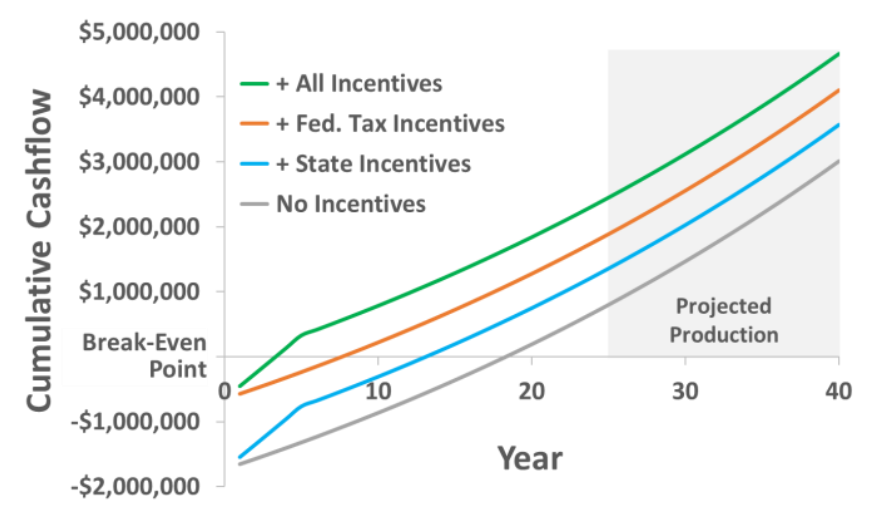

Figure 3: The effects of federal tax incentives and incentives in the state of Illinois on the cost-benefit projections for a 1,000-kilowatt solar project. The effect of the state incentives is observed over the first five years, because Illinois credits solar developers incrementally over that timeframe. The breakeven point for each example occurs when the line crosses the $x$-axis. Projections for after year 25 depend upon an extended lifespan of the solar panels, and so are less certain.

\section{ii. Options for financing solar projects}

Another key benefit of government incentivization of solar developments is that it has driven investors to offer attractive financing options for end-users. For example, in many states, if a residence, company, or other organization lacks the capital to pay for the upfront costs of a solar array, it may opt into a purchase power agreement (PPA). Under this arrangement, an investor purchases and builds an array on the end-user's property, and then sells the generated electricity to that end-user at a discount compared to the traditional electrical rate (Halper 2014). A PPA is advantageous for the end-user because it requires no upfront funds for the solar array, and most of the risk for the project is assumed by the financier. The only risk to the end-user is that a PPA usually requires a commitment to not disrupt the array with a construction project or change in property ownership (so for a rooftop array, newer roofs are the best locations for installation). The disadvantage is that the financier will reap more of the savings, and the end-user will profit less.
Another financing option is a hybrid between a PPA and a cash purchase, where the end-user starts with a PPA, but then gradually acquires ownership of the array over time. This model can be particularly attractive for non-taxed entities, such as charities or universities, as they can use a for-profit financier who will earn the federal tax credits and then sell the array back to the user at a lower rate (this is legal in states that allow for PPAs).

These three financial models (including an upfront cash purchase made by the end-user) can be viewed as a continuum that balances the trade-offs between profit and risk avoidance (see Figure 4). On one extreme is the upfront cash purchase, while the full PPA option is on the other; the hybrid model can lie anywhere in between the extremes, depending on the desired length of term for the PPA. The more upfront capital the end-users invest, the more profit they may realize; however, they also must accept more risk. Less upfront capital means less profit, but also less risk. Having multiple financing options available encourages more end-users to transition to solar power, and these options likely would not be available without government incentive programs that drive investment.

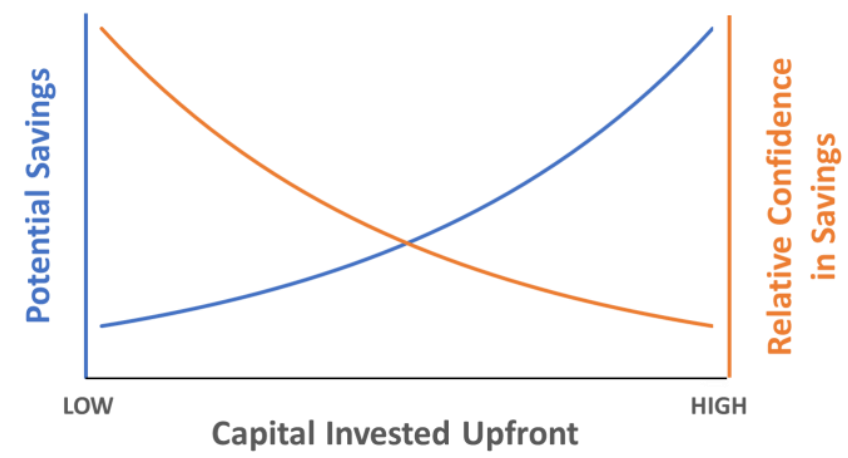

Figure 4: Potential financial savings and risk for a solar project, as a function of the amount of initial funds invested at the outset. Solar development companies offer a variety of options for financing new arrays, ranging from $0 \%$ upfront capital required to $100 \%$ ownership. More capital invested upfront means greater potential energy savings for the end-user, but also more risk, here depicted as less confidence in the potential savings. A "middle ground" option may be preferable, where there is reasonable confidence of moderately high savings. 


\section{Environmental and financial cost-benefit analyses}

\section{i. Quantitative parameters}

Potential end-users of solar can accurately estimate the positive environmental impact and the profitability of an array given some basic input data. The quantity of carbon dioxide emissions avoided by using solar energy instead of fossil fuel combustion can be easily calculated at the US EPA's website (www.epa.gov/energy/greenhouse-gas-

equivalencies-calculator). Furthermore, the amount of sunlight received at a specific location in the US can be accurately estimated for free using Google's Project Sunroof (www.google.com/get/sunroof). This database takes into account decades of weather data for specific locations.

Other parameters to consider are the following: the lifespan of the panels (typically guaranteed for 25 years, although more than 40 years of energy production have been reported (Jordan and Kurtz 2013); the panel degradation rate (typical panels degrade at a rate of $0.5 \%$ per year (Jordan and Kurtz 2013); current and future costs of utility-provided electricity (the average electrical rate for the US is 10.3 cents per $\mathrm{kWh}$, with an average annual price escalation of $3.6 \%$ (U.S. Energy Information Administration, 2019); and ongoing operations and maintenance costs (it is advisable to set aside $0.5 \%$ of the total array cost each year for these expenses, which include replacing the panel inverters after about 12 years).

We have developed a tool (available here) that allows readers to input their own unique parameters and estimate outcomes. An example analysis for a 1,000 kilowatt array is displayed in Table 1 . One advantage of this tool is that it allows users to easily see the impact that government incentives can have on the profitability of a solar installation. Users can see how much money they are estimated to save each year, and when they can expect to break even (recoup the upfront purchase costs). Additionally, the tool automatically calculates the quantity of carbon dioxide emissions avoided by not generating the electricity through fossil fuel combustion, and also expresses this amount in more familiar terms as gallons of gasoline used by a vehicle ("Greenhouse Gases Equivalencies Calculator - Calculations and References" n.d.). We believe that having access to this tool will help organizations see the financial and environmental benefits of converting to solargenerated electricity.

\section{ii. Qualitative parameters}

Besides the quantitative parameters included in the cost-benefit estimator, some qualitative factors should be considered by potential solar users as well. The most efficient arrays will be those that are unshaded and that are flat or tilted in the direction of the equator. Rooftop arrays are ideal because they do not take up valuable land space. However, the lifespan of the roof must be considered, as arrays would have to be taken down and reinstalled in the event of roof replacement. Ideally, solar arrays would be built on newer roofs with long lifespans (20 years or more). Figure 5 provides an example of an ideal rooftop for solar development.

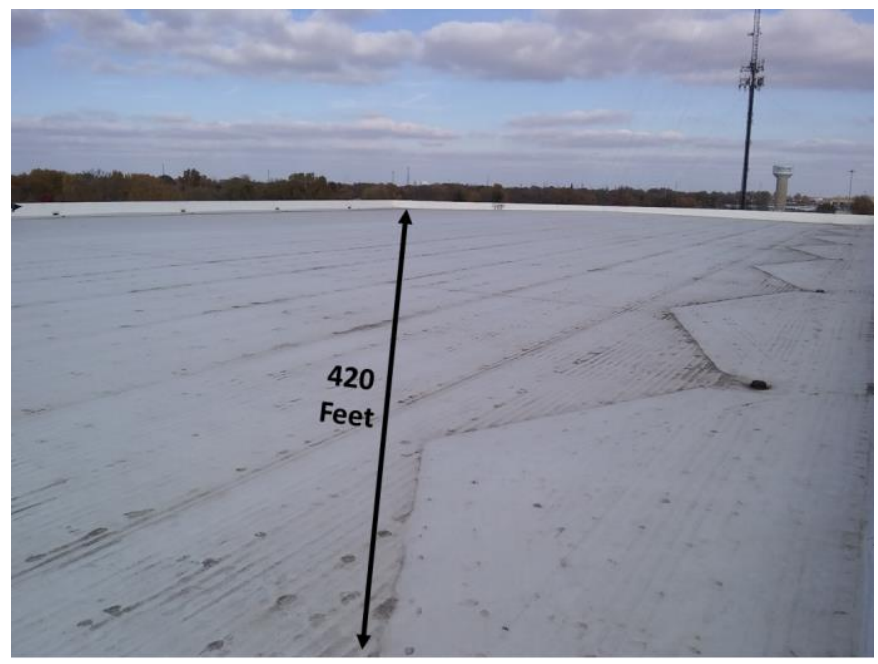

Figure 5: An example of an ideal rooftop for a solar installation. The roof is unshaded and has few mechanical obstructions on the surface. It is a recently installed roof with maximal longevity. The installed solar array should be flat or tilted in the direction of the equator.

\section{Policy recommendation}

In order to continue transitioning the country from fossil fuels to renewable energy sources, the federal government and state governments should continue to incentivize solar developments through the use of tax credits and cost-sharing programs. Specifically, the federal government should extend the income tax credit at a rate of $30 \%$ until 2030 . The state of Illinois should renew its SREC program and set a new goal of achieving $40 \%$ sustainable energy production by 2030 , and $100 \%$ by 2050 . Other states that have not 


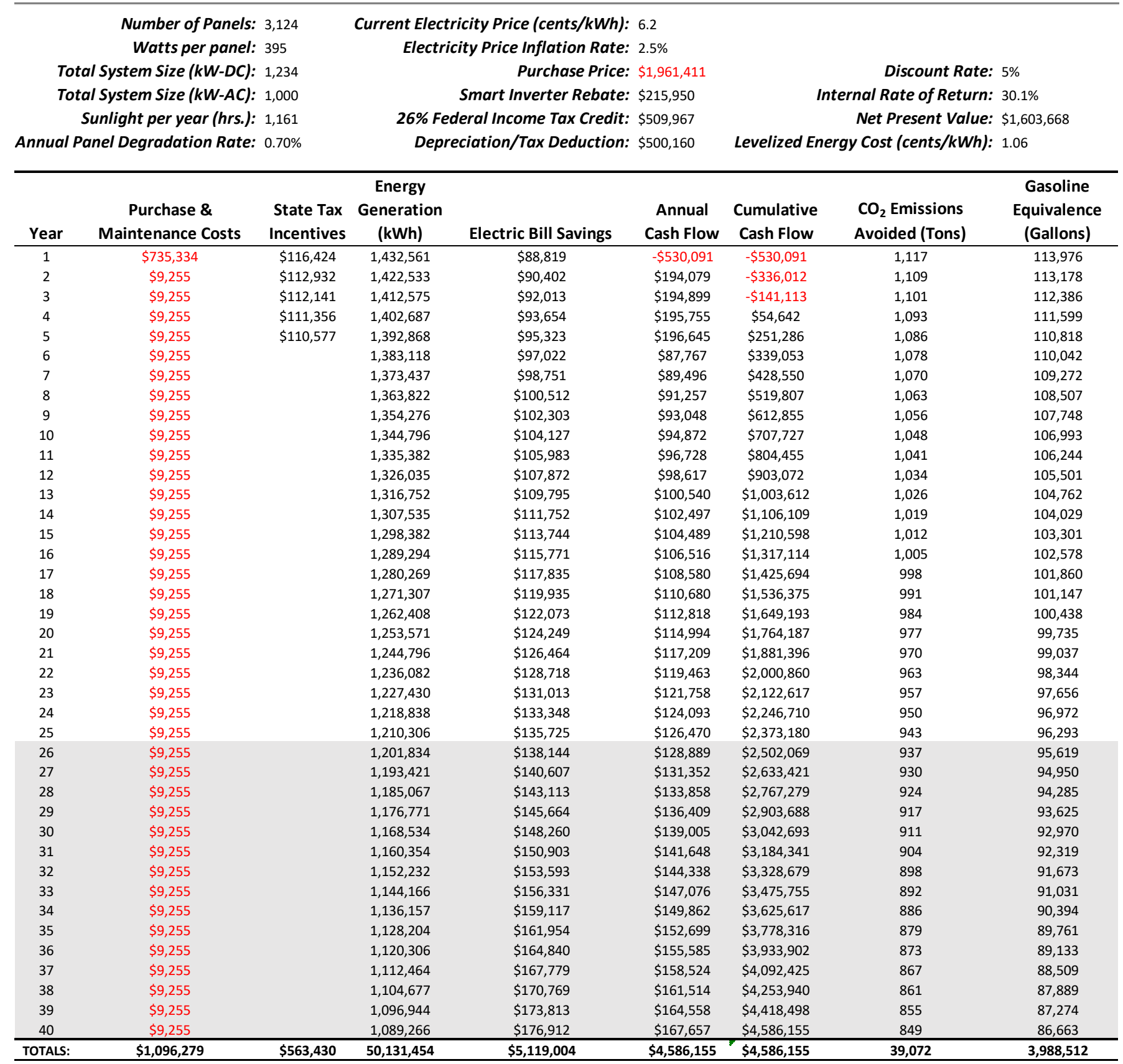

Table 1: 40-year financial and environmental cost-benefit analysis of a 1,000 kilowatt solar installation. Red values are costs; black values are benefits. The specific parameters used for this example are at the top of the table and are derived from an actual solar array design proposal. Projections for after year 25 assume an extended lifespan of the solar panels, and so are less certain. Readers can download this table here in order to put in their own parameters and obtain a custom cost-benefit analysis.

yet done so should enact similar programs. Helping developers with the upfront costs of renewable energy will encourage more organizations to make the transition, thereby helping humanity reach the Paris Agreement target and avoid catastrophic climate change. Studies have shown that government incentives positively impact solar energy development (Thomas 2020; Ryan, Donou-Adonsou, and Calkins 2019). Indeed, before enhancing their incentive programs, even sunny states such as Florida and South Carolina had relatively few solar installations deployed (Halper 2014). Now, both states are among the top 15, in terms of their total installed solar generating capacity (Solar Energy Industries Association 2020). Ending government 
incentivization of solar energy now would slow this progress towards sustainable energy production.

\section{Conclusion}

The analysis tool provided here is designed to help consumers assess the positive environmental impact and financial profitability of a solar array with confidence. It also demonstrates that although solar arrays will generally pay for themselves without incentives over time, government incentive funds can dramatically shorten the time until the break-even point, which drives investors and developers to build

\section{References}

British Petroleum. 2019. "BP Statistical Review of World Energy 2019, No.68." British Petroleum (Bp). https://www.bp.com/content/dam/bp/business -sites/en/global/corporate/pdfs/energyeconomics/statistical-review/bp-stats-review2019-full-report.pdf

Crabtree, George W., and Nathan S. Lewis. 2007. "Solar Energy Conversion." Physics Today. https://doi.org/10.1063/1.2718755.

Funk, C., \& Kennedy, B. 2019. "How Americans See Climate Change in 5 Charts." Pew Research Center. 2019. https://www.pewresearch.org/facttank/2019/04/18/a-look-at-how-peoplearound-the-world-view-climate-change/

Goodstein, Eban, and L Hunter Lovins. 2019. "A Pathway to Rapid Global Solar Energy Deployment? Exploring the Solar Dominance Hypothesis." Energy Research \& Social Science 56 (May): 101197. https://doi.org/10.1016/i.erss.2019.05.007.

"Greenhouse Gases Equivalencies Calculator - Calculations and References." n.d. Accessed July 14, 2020. https://www.epa.gov/energy/greenhouse-gasesequivalencies-calculator-calculations-andreferences.

Halper, E. 2014. "Rules Prevent Solar Panels in Many States with Abundant Sunlight." Los Angeles Times, 2014. https://www.latimes.com/nation/la-na-no-solar20140810-story.html

IPCC. 2014. "Climate Change 2014 Synthesis Report Summary Chapter for Policymakers." Ipcc. https://doi.org/10.1017/CB09781107415324.

Jordan, D. C., and S. R. Kurtz. 2013. "Photovoltaic Degradation Rates - An Analytical Review." Progress in Photovoltaics: Research and Applications. https://doi.org/10.1002/pip.1182.

Lazard. 2018. "Lazard's Levelized Cost of Energy Analysis - Version 12.0." Lazard. https://www.lazard.com/media/450784/lazar ds-levelized-cost-of-energy-version-120vfinal.pdf solar projects. Economist Isidor Wallimann defines "sustainability" as "a societal pattern of interaction with nature which assures a very long-term output and distribution mode sufficient for all to live in dignity and in accord with the average longevity potential" (Wallimann 2013). In order to move the global economy towards a state of sustainability, governments should continue to aggressively incentivize solar energy. This will prompt more consumers to transition to solar power and thereby reduce greenhouse gas emissions and slow climate change.

Lydersen, K. 2020. 'Facing Coronavirus and a 'cliff,' Can Illinois Solar Survive?" Energy News Network, May 4, 2020. https://energynews.us/2020/05/04/midwest/fa cing-coronavirus-and-a-cliff-can-illinois-solarsurvive/

Myers, Q. 2019. "Illinois Faces Challenges in Reaching Renewable Energy Goals." WTTW. 2019. https://news.wttw.com/2019/07/24/illinoisfaces-challenges-reaching-renewable-energygoals.

Perez, R., and M. Perez. 2009. "A Fundamental Look At Energy Reserves For The Planet." The International Energy Agency SHC Programme Solar Update. http://www.asrc.cestm.albany.edu/perez/Kit/pd f/a-fundamental-look-at\%20the-planetaryenergy-reserves.pdf

Ruppenthal, A. 2019. "Illinois Defies National Trend by Adding 1,300 Solar Jobs in 2018." WTTW, February 13 , 2019. https://news.wttw.com/2019/02/13/illinoissolar-jobs-report

Ryan, A. J., Ficawoyi D., \& Calkins, L. N. 2019. "Subsidizing the Sun: The Impact of State Policies on Electricity Generated from Solar Photovoltaic." Economic Analysis and Policy. https://doi.org/10.1016/j.eap.2019.04.012.

Solar Energy Industries Association. 2020. "Solar Industry Research Data." 2020. https://www.seia.org/solar-industry-researchdata.

Stokes, L. C., and Hanna L. B. 2018. "Politics in the U.S. Energy Transition: Case Studies of Solar, Wind, Biofuels and Electric Vehicles Policy." Energy Policy. https://doi.org/10.1016/j.enpol.2017.10.057. 
Thomas, M. D. 2020. "Econometric Determinants of Residential Solar Development in the United States." The University of North Carolina at Charlotte.

https://search.proquest.com/openview/6d978a 03238602d440fa4a19244d74e2/1?pqorigsite $=$ gscholar $\& \mathrm{cbl}=18750 \&$ diss $=y$

U.S. Energy Information Administration. 2019. "September 2019 Monthly Energy Review.” U.S. Energy Information Administration. https://www.eia.gov/totalenergy/data/monthly /archive/00351909.pdf

United Nations. 2015. "Summary of the Paris Agreement." United Nations Framework Convention on Climate Change. https://unfccc.int/process-andmeetings/the-paris-agreement/what-is-theparis-agreement
Wallimann, I. 2013. Environmental Policy Is Social PolicySocial Policy Is Environmental Policy: Toward Sustainability Policy. https://doi.org/10.1007/978-1-4614-6723-6.

Warburg, P. 2019. "An Introduction to the State of Solar Power in the U.S." Yale Climate Connections. 2019. https://www.yaleclimateconnections.org/2019/ 08/an-introduction-to-the-state-of-solar-powerin-the-u-s/.

Weckend, S., Andreas, W., \& Garvin H. 2016. End-of-Life Management: Solar Photovoltaic Panels. Golden, CO:

NREL. https://www.irena.org/documentdownloads/pu blications/irena ieapvps end-oflife solar pv panels 2016.pdf

Ryan Himes is a professor of biology at Olivet Nazarene University in Bourbonnais, IL. He earned his Ph.D. in human physiology from Loyola University Chicago, in the laboratory of Dr. Seth Robia.

London Withers is pursuing an environmental science bachelor's degree at Olivet Nazarene University in the Honors Program. She plans to continue research with Dr. Himes on other environmental issues, specifically recycling programs.

Alyssa Black is currently in pursuit of a biology degree with a minor in chemistry at Olivet Nazarene University. She hopes to further involve herself in matters concerning environmental reform throughout her lifetime while also working in the medical field. 